\title{
A case of postpartum hemorrhage and sterilization in the developing world
}

\author{
Mark H. Crouch* \\ Nazarene General Hospital, Kudjip, Jiwaka, Papua New Guinea and In His Image International, Tulsa, Oklahoma, \\ USA
}

Received: 02 June 2017

Accepted: 29 June 2017

*Correspondence:

Dr. Mark H. Crouch,

E-mail: crouchm@gmail.com

Copyright: ( $\odot$ the author(s), publisher and licensee Medip Academy. This is an open-access article distributed under the terms of the Creative Commons Attribution Non-Commercial License, which permits unrestricted non-commercial use, distribution, and reproduction in any medium, provided the original work is properly cited.

\begin{abstract}
A woman delivers a term infant vaginally at a district hospital in Papua New Guinea complicated by a retained placenta, uterine inversion and post-partum hemorrhage. A tubal ligation to protect the life of the mother from possibly fatal complications in future pregnancy is suggested, but the couple's cultural beliefs make this a challenge. This case illustrates the impact of post-partum hemorrhage in a developing world context and cultural issues related to sterilization performed in these settings to protect the life of the mother.
\end{abstract}

Keywords: Post-partum hemorrhage, Sterilization, Uterine tamponade

\section{INTRODUCTION}

Maternal conditions represent a significant global disease burden, causing roughly $2 \%$ of all deaths in women (over 500,000 ) each year. ${ }^{1,2}$ More than $99 \%$ of these lives are lost in the developing world. ${ }^{3}$ By some estimates, postpartum hemorrhage accounts for $28 \%$ of these deaths in low- and middle-income countries. ${ }^{4}$ This means about 140,000 women die from bleeding at childbirth every year in low- and middle-income nations. In Papua New Guinea, hemorrhage is the third-leading cause of maternal death, behind abortion and sepsis. ${ }^{5}$

Risk factors for post-partum hemorrhage include history of post-partum hemorrhage, prolonged labor, abnormal placentation, multiple gestation, and operative vaginal delivery. ${ }^{6}$ For women at a high risk of morbidity or mortality from post-partum hemorrhage, thought should be given to family planning or contraception measures to protect the life of the patient. The most used technique of contraception in the world is sterilization, used by 187 million women worldwide. ${ }^{3}$ However, a significant barrier to contraception in general, and sterilization in particular, includes social acceptability. ${ }^{3}$ In Papua New Guinea, the standard treatment guidelines in obstetrics recommend that a woman's husband be consulted before performing sterilization, but maintain that the ultimate decision on sterilization should be made by the woman planning to undergo the procedure. ${ }^{7}$

The following report documents a case of retained placenta leading to massive post-partum hemorrhage in a Melanesian woman resulting in the medical recommendation of sterilization to protect the life of the mother, but which encountered resistance from the patient's spouse.

\section{CASE REPORT}

A Melanesian woman of about 30 years of age presented to the labor and delivery unit of our district hospital in Papua New Guinea at 40 weeks gestation (by last 
menstrual period and fundal height measurement) complaining of contractions for 12 hours and rupture of amniotic membranes for 15 hours. She had two previous pregnancies resulting in vaginal deliveries with retained placenta complicated by post-partum hemorrhage on both occasions.

On admission, vital signs were normal (blood pressure $134 / 82 \mathrm{mmHg}$, pulse 82 beats per minute and temperature afebrile), fetal heart rate was 140 beats per minute. Her cervix was completely dilated. The baby was oriented in vertex longitudinal lie but with face presentation.

Her second stage of labor was augmented with oxytocin infusion and she delivered a vigorous female infant. After 30 minutes, the placenta had not delivered with controlled cord traction and the patient was given misoprostol $600 \mathrm{mcg}$ per rectum and 20 units IV oxytocin infusion in normal saline at $250 \mathrm{~mL} /$ hour due to mild bleeding. After a further 30 minutes with persistent retained placenta the patient's bleeding increased and the supervising physician was notified.

On physician arrival, the patient was awake and alert but slightly pale with bleeding from the retained placenta and a blood pressure of 70/40 and pulse of 124 . Her bladder was emptied via straight urinary catheterization returning about $200 \mathrm{~mL}$ of clear urine. Intravenous ketamine and diazepam sedation was used to facilitate manual removal of the retained placenta. During placenta extraction, the uterus was inverted and promptly restored in the usual fashion. A curettage returned very little tissue but the patient continued to bleed heavily despite firm bi-manual uterine compression. Two units of whole blood were prepared for transfusion while ergometrine was given intramuscularly. Without access to specific uterine tamponade balloons, a large caliber foley catheter was place into the uterus with $120 \mathrm{~mL}$ of sterile water into the foley bulb in an effort to tamponade the patient's bleeding. This was successful in reducing hemorrhage and the patient's blood pressure increased to 90/60 and pulse decreased to 112 . The foley balloon was left in place and two units of whole blood transfused overnight. Her total estimated blood loss was $2000 \mathrm{~mL}$.

On post-partum day 1 , the patient's bleeding was controlled. The uterine balloon was left in place. After two units of whole blood, the patient's hemoglobin concentration was $5.8 \mathrm{~g} / \mathrm{dL}$. Her blood pressure remained low and her tachycardia persisted. The patient was advised that future pregnancies could possibly result in the same outcome and potentially claim the patient's life. For this reason, tubal ligation was recommended. The patient advised the medical team that because she was a woman, she could not make this decision and that "the Bible says my husband must make it." The patient was transfused with a third unit of whole blood. On postpartum day 2, the patient's hemoglobin was $7.1 \mathrm{~g} / \mathrm{dL}$, blood pressure was $100 / 80$ and pulse of 92 . The uterine balloon was discontinued and her bleeding had ceased. She consented to tubal ligation, but deferred the procedure until her husband, who worked in another province, could arrive to make the final decision for her.

On post-partum day 6 , the patient's husband arrived. He initially showed concern for his wife and suggested that he would be open to tubal ligation. However, when asked to sign for written consent he raised numerous objections.

- The cost of the procedure

- Recovery time

- Long-term future adverse effects of surgery like uterine cancer

- Procedure limiting patient's ability to work in the future

- Request to take the patient home for a week and then return to have the procedure.

After discussing each of these issues thoroughly, the husband and patient agreed and consented to sterilization by tubal ligation which was performed on post-partum day 7 . The patient discharged home on post-partum day 8 with a hemoglobin of $8.6 \mathrm{~g} / \mathrm{dL}$ without further complications.

\section{DISCUSSION}

Post-partum hemorrhage managed in low-resource settings can be life-saving. ${ }^{1,8}$ Consistent with national guidelines, in our facility, nurses and midwives are trained to provide active management of the third stage of labor with intramuscular oxytocin and controlled cord traction for placental delivery. ${ }^{7}$ If bleeding persists or increases, rectal misoprostol, intravenous oxytocin infusion and bladder decompression are performed while notifying the supervising physician. In this case, active management of the third stage as well as the initial treatment of post-partum hemorrhage were appropriately implemented according to institution protocols with the exception of not performing immediate bladder decompression. After initially seeing a reduction in hemorrhage, the retained placenta led to further bleeding necessitating more aggressive maneuvers. This culminated in the creative use of a foley catheter with high-volume bulb expansion to tamponade the uterine bleeding while transfusion of blood products commenced, a recognized stabilizing maneuver. ${ }^{1}$ Because of the extreme measures needed to save this patient's life, tubal ligation was discussed as a means to protect her from similar complications and possible fatality in future pregnancy.

For patients in whom significant risk factors for developing complications in future pregnancies exist, sterilization ought to be discussed as a means of protecting the life of the mother. This is particularly true in low- and middle-income countries where fewer births occur in facilities capable of dealing with complications or providing blood transfusions. In some of these settings, 
however, there exists a cultural resistance toward sterilization. ${ }^{7}$ In part, this could be due to a cultural propensity toward having larger families. ${ }^{3}$ In our case, the challenge lay more in the decision-making ability of women in regards to their fertility. This difficulty regarding gender-based power discrepancy likely exists in other parts of the world. In this case, this issue was further complicated by the religious beliefs of the couple involved. Only after extensive discussion with the husband and the affirmation of his consent did our patient agree to sterilization, although by Papua New Guinea law the final decision should lay with her.

\section{CONCLUSION}

Retained placenta and post-partum hemorrhage can be catastrophic events complicating the third stage of labor and require prompt management to prevent maternal morbidity and mortality. In resource-poor settings this may involve creative stabilizing techniques, particularly if definitive surgical treatment is not immediately available.

Sterilization remains a culturally sensitive topic even when medically advised to protect the life of a mother. Social issues surrounding sterilization include family size norms, the decision-making role of women and religious beliefs as well as others that likely vary by the specific cultural setting.

\section{ACKNOWLEDGMENTS}

Authors would like to thank the staff of Nazarene General Hospital for their dedicated efforts to protect the life of this patient.
Funding: No funding sources Conflict of interest: None declared

Ethical approval: Not required

\section{REFERENCES}

1. Etches D, Hecox K. Post-partum hemorrhage. In: Dresang LT, Leeman L, Gipson TF, eds. Global Advanced Life Support in Obstetrics. $1^{\text {st }}$ ed. Laewood, Kansas. American Academy of Family Physicians, 2009:70-6.

2. The Global Burden of Disease 2004 Update. Geneva, Switzerland: World Health Organization; 2008.

3. Jamison DT, Breman JG, Measham AR, Alleyne G, Claeson M, Evans DB, et al. Priorities in Health. Washington, DC: The World Bank; 2006.

4. Skolnik, RL. Global Health 101. $2^{\text {nd }}$ ed. Burlington, MA: Jones and Bartlett Learning. 2012:185-207.

5. WHO. Papua New Guinea Country Health Information Profile. Geneva, Switzerland: World Health Organization; 2011.

6. Leeman L. advanced life support in obstetrics course syllabus. Laewood, Kansas. American Academy of Family Physicians Section J; 2009.

7. Mola G. Manual of Standard Managements in Obstetrics and Gynecology for Doctors, H.E.O.s and Midwives in Papua New Guinea. $6^{\text {th }}$ ed. Port Moresby, Papua New Guinea: National Department of Health; 2010:65-71.

8. The World Bank. Disease Control Priorities in Developing Countries. 2nd Edition. World Bank and Oxford University Press, New York, USA; 2006.

Cite this article as: Crouch MH. A case of postpartum hemorrhage and sterilization in the developing world. Int J Reprod Contracept Obstet Gynecol 2017;6:3657-9 